\title{
Gas chromatography-Mass spectrometry analysis of bioactive compounds in chloroform extract of Psoralea corylifolia L.
}

\author{
S. Ranjith Kumar ${ }^{*}$ \\ Department of Sericulture, Forest College and Research Institute, Tamil Nadu Agricultural \\ University, Mettupalayam - 641301 (Tamil Nadu), India \\ K. Chozhan \\ Department of Sericulture, Forest College and Research Institute, Tamil Nadu Agricultural \\ University, Mettupalayam - 641301 (Tamil Nadu), India \\ K. A. Murugesh \\ Department of Sericulture, Forest College and Research Institute, Tamil Nadu Agricultural \\ University, Mettupalayam - 641301 (Tamil Nadu), India

\section{R. Rajeswari} \\ Department of Sericulture, Forest College and Research Institute, Tamil Nadu Agricultural \\ University, Mettupalayam - 641301 (Tamil Nadu), India \\ K. Kumaran \\ Department of Forest Biology and Tree Improvement, Forest college and Research Institute, \\ Tamil Nadu Agricultural University, Mettupalayam - 641301 (Tamil Nadu), India \\ *Corresponding author: E mail: ranjithsiva1294@gmail.com
}

\section{How to Cite}

Ranjith Kumar, S. et al. (2021). Gas chromatography-Mass spectrometry analysis of bioactive compounds in chloroform extract of Psoralea corylifolia L.. Journal of Applied and Natural Science, 13(4), 1225 - 1230. https://doi.org/10.31018/jans.v13i4.2884

\begin{abstract}
Psoralea corylifolia is the most important medicinal plant which has various secondary metabolites and its leaves are broadly used in many sectors due to its antimicrobial activity. This study aimed to find the bio-active compounds of chloroform extract of P. corylifolia leaves using Perkin-Elmer Gas Chromatography - Mass Spectrometry (GC-MS). The results of GC-MS compounds in the chloroform extract was appropriate to the database of National Institute of Standards and Technology (NIST). GC -MS analysis of chloroform extract of $P$. corylifolia leaves reveal the presence of bioactive compounds as Hexadecanoic acid, 3hydroxy-, methyl ester, Hydroxylamine, O-decyl- , 2,4-Di-tert-butylphenol ) Cubenol, Neophytadiene, Phytol , Linoleic acid ethyl esterand 9,12,15-Octadecatrienoic acid, ethyl ester, (Z,Z,Z)- ). These bio-active compounds are mainly responsible for various biological activities. Hence, this study will make a good way for the production of various products for curing various disease-causing pathogens by using $P$. corylifolia leaves.
\end{abstract}

Keywords: Psoralea corylifolia, GC-MS, antimicrobial, bio-active compounds

\section{INTRODUCTION}

The importance of therapeutic herbs is well-known even in ancient times. There were no synthetic medicines available at the time, thus people relied solely on natural treatments to treat any illnesses. As a result, it was assumed that all plants possess a diverse set of medical properties and are immensely useful to human health and well-being. To discover more about the medicinal properties of plants, biological study is required (Sofowora et al. 2013). However, many therapeutic plants and their medical characteristics have yet to be discovered. Only $6 \%$ of the $4,00,000$ plant species have been researched for biological function, and only a few have been investigated phytochemically (International Union for Conservation of Nature and Natural Resources, 2013). This demonstrates that many medicinal plants require research on their activity and pharmacological qualities. Additionally, plant medicines' recent return can be attributed to a number of factors, including their effectiveness and lack of adverse effects when compared to contemporary pharmaceuticals. Psoralea corylifolia, often known as babchi, is a prominent herb that has been utilized in traditional Ayurvedic and Chinese medicine for its miraculous benefits in the treatment of numerous skin disorders for a long time (Siva 
et al., 2015). Chemoprotective, antioxidant, antibacterial, and anti-inflammatory effects of this plant are also being researched pharmacologically (Zhang et al., 2016). Apart from the fact that key constituents of $P$. corylifolia performed a wide spectrum of biological functions, the precise biological actions of the plant chemical constituents have remained elusive, and just a few chemicals identified from this plant have been used for medications. With the medicinal properties of $P$. corylifolia in mind, the present study aimed to identify bioactive compounds of the leaves of this plant, categorizing each specific compound with its concentration using Gas Chromatography-Mass Spectrometry (GC-MS) analysis, and elucidating their chemical composition and biological activity.

\section{MATERIALS AND METHODS}

\section{Collection of plant materials}

$P$. corylifolia (Fabaceae) leaves were taken from medicinal plants block which was maintained by the Department of Sericulture, Forest College and Research Institute, Tamil Nadu Agricultural University, Mettupalayam, (Tamil Nadu). It is located at $11.20^{\circ}$ North Latitude and $76.56^{\circ}$ East Longitude at an altitude of $320 \mathrm{~m}$ above mean sea level.

The height of the plant was about $30-170 \mathrm{~cm}$ grown under the warm condition in sandy loam soil. The flowers are small in size with purple colour. The leaves are the simple, broad and blunt end with white hairs on the upper and lower surfaces of leaves and its arrangement is racemes. The collected leaves were shade dried, powdered and used for the study.

\section{Preparation of plant extract}

$25 \mathrm{~g}$ of the powdered leaves of medicinal plant $P$. corylifolia were weighed separately in chloroform and percolated overnight. The sample tube of the unit was fitted with a filter disc at the bottom and filled with ground samples, sealed with another filter disc and compressed. This was fitted to an electric heating mantle with Soxhlet unit, filled with $250 \mathrm{ml}$ chloroform, and a temperature of $60^{\circ} \mathrm{C}$ was maintained for 6 hours. The residual extract was collected in a flask and transferred to a rotary flask vacuum evaporator for evaporation of the solvent. The residue thus obtained was stored at $4^{0} \mathrm{C}$ in airtight bottles for future use.

\section{GC-MS analysis}

The GC-MS (GC-7890A, MS 5975C) with Fused silica $15 \mathrm{~m} \times 0.2 \mathrm{~mm}$ ID $\times 1 \mathrm{~m}$ capillary column was utilized for the GC-MS study. The instrument was set to an initial temperature of $110{ }^{\circ} \mathrm{C}$ and kept at that temperature for 2 minutes. The oven temperature was raised to $280{ }^{\circ} \mathrm{C}$ at a rate of $5{ }^{\circ} \mathrm{C} / \mathrm{min}$ after this time and sustained for 9 minutes. The injection port temperature was kept at $250^{\circ} \mathrm{C}$, while the flow rate of helium was kept at $1 \mathrm{ml}$ min. $70 \mathrm{eV}$ was used as the ionization voltage. The sample was injected in a 10:1 split mode. The range of mass spectral scans was chosen to $30-450(\mathrm{~m} / \mathrm{z})$. The substances included in the plant's sample were identified using computer searches on a NIST Ver.2.1 MS data library and comparing the spectrum obtained using GC-MS (Fig . 1).

The National Institute of Standards and Technology (NIST) database, which contains over 62,000 patterns was used to interpret the mass-spectrum GC-MS results. The unknown components' spectra were compared to the spectrum of known components recorded in the NIST library. The components of the test materials were identified by their name, molecular weight, and structure.

\section{RESULTS AND DISCUSSION}

\section{Identified bio-active compounds in P. corylifolia leaves}

The phytochemical substances were confirmed using peak area, retention time, and molecular formula. The various active compounds in a chloroform extract of $P$. corylifolia leaves viz.Hexadecanoic acid, 3-hydroxy-, methyl ester (3.02), Hydroxylamine, O-decyl- (4.92), 2,4-Di-tert-butylphenol (13.05), Cubenol (15.12), Neophytadiene (20.08), Phytol (25.30), Linoleic acid ethyl ester (25.02), 9,12,15-Octadecatrienoic acid, ethyl ester, (Z,Z,Z)- (26.37) along with their retention time (RT), molecular formula, molecular weight (MW), and peak area are listed in Table 1, In respect of identified compunds, Neophytadiene (20.08), Phytol (25.30), Linoleic acid ethyl ester (25.02), 9,12,15-Octadecatrienoic acid, ethyl ester, (Z,Z,Z)- (26.37) had higher peak area with maximum retention time compared to others due to presence of higher amount of these compounds in the P.corylifolia leaves. Compared to other medicinal plants, $P$. corylifolia has significant medicinal plant with a long history of therapeutic use and most of the research done on $P$. corylifolia seeds and fruits. This is the first report on identification of bioactive compounds in the $P$. corylifolia leaves. The presence of twenty chemicals (phytochemical ingredients) was found by GC-MS analysis of P.corylifolia leaves, indicating the plant's therapeutic properties. The compounds have a wide range of biological characteristics. The biological activities of the plants can be determined by GC-MS analysis of phyto-constituents. Earlier, Sathish et al. (2012) identifed the compounds-as tetradecanoic acid, n-hexadecanoic acid, 12- octadecanoic acid, dodecanoic acid, dibutyl ester, ethyl ester, and 9, 12 - octadecadienoic $(Z, Z)$ in the Vitex altissima plant. Similarly, Kumar and Manimegalai (2008) found phytol in the leaves of Lantana camara, and Sridharan et al. (2011) found it in the leaves of Mimosa pudica. 


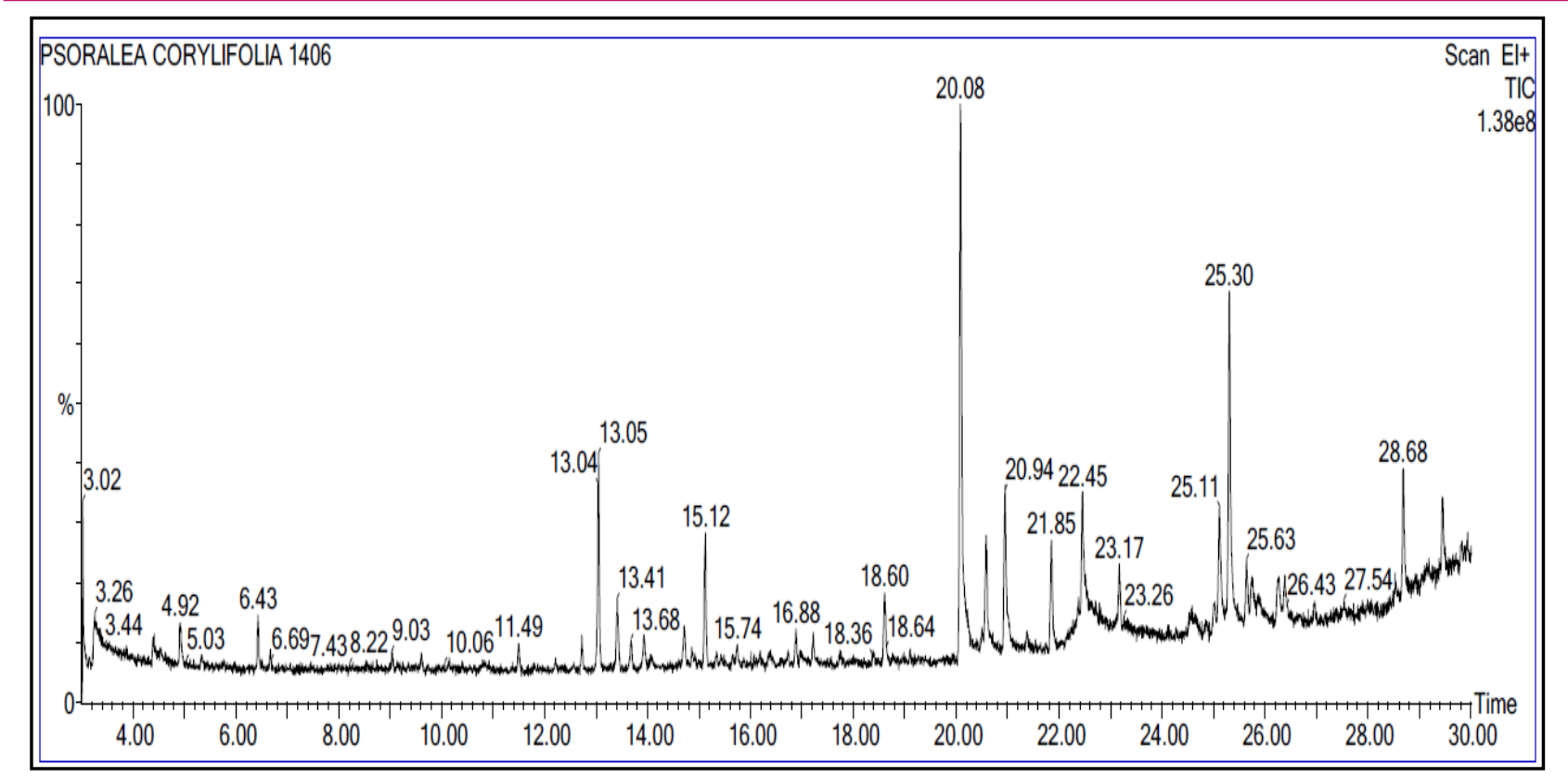

Fig. 1. GC-MS chromatogram of Psoralea corylifolia leaf extract showing the peaks of bio-active compounds

Table 1. Bioactive compounds present in the chloroform extract of Psoralea corylifolialeaves as revealed by GC-MS analysis

\begin{tabular}{|c|c|c|c|c|c|c|}
\hline S.No. & Retention & Area (\%) & Name of the compound & Molecular & Molecular & Functional \\
\hline 1. & 3.02 & 1.25 & $\begin{array}{l}\text { Hexadecanoic acid, 3-hydroxy-, } \\
\text { methyl ester }\end{array}$ & $\mathrm{C}_{17} \mathrm{H}_{34} \mathrm{O}_{3}$ & 286.45 & $\begin{array}{l}\text { Ester of fatty } \\
\text { acid }\end{array}$ \\
\hline 2. & 3.25 & 1.79 & Tiglic acid & $\mathrm{C}_{5} \mathrm{H}_{8} \mathrm{O}_{2}$ & 100.11 & Fatty acid \\
\hline 3. & 4.92 & 0.71 & Hydroxylamine, O-decyl- & $\mathrm{C}_{10} \mathrm{H}_{23} \mathrm{NO}$ & 173.29 & Amines \\
\hline $\begin{array}{l}4 . \\
5 .\end{array}$ & $\begin{array}{l}6.43 \\
12.72\end{array}$ & $\begin{array}{l}0.65 \\
0.42\end{array}$ & $\begin{array}{l}\text { Tetradecane } \\
\text { Germacrene D }\end{array}$ & $\begin{array}{l}\mathrm{C}_{14} \mathrm{H}_{30} \\
\mathrm{C}_{15} \mathrm{H}_{24}\end{array}$ & $\begin{array}{l}198.39 \\
204.35\end{array}$ & $\begin{array}{l}\text { Alkanes } \\
\text { Terpenoids }\end{array}$ \\
\hline 6. & 13.05 & 2.56 & 2,4-Di-tert-butylphenol & $\mathrm{C}_{14} \mathrm{H}_{22} \mathrm{O}$ & 206.32 & Phenols \\
\hline 7. & 13.41 & 0.95 & á-copaene & $\mathrm{C}_{15} \mathrm{H}_{24}$ & 204.35 & Terpenoids \\
\hline 8. & 13.92 & 0.56 & $\begin{array}{l}\text { 7-epi-trans-sesquisabinene hy- } \\
\text { drate }\end{array}$ & $\mathrm{C}_{15} \mathrm{H}_{26} \mathrm{O}$ & 222.37 & Aromatic \\
\hline 9. & 14.70 & 0.67 & Aromandendrene & $\mathrm{C}_{15} \mathrm{H}_{24}$ & 204.35 & Aromatic \\
\hline 10. & 15.12 & 1.63 & Cubenol & $\mathrm{C}_{15} \mathrm{H}_{26} \mathrm{O}$ & 222.36 & Terpenoids \\
\hline 11. & 18.60 & 1.12 & $\begin{array}{l}\text { 6-Hydroxy-4,4,7a-trimethyl- } \\
5,6,7,7 \mathrm{a} \text {-tetrahydrobenzofuran-2 } \\
\text { (4H)-one }\end{array}$ & $\mathrm{C}_{11} \mathrm{H}_{16} \mathrm{O}_{3}$ & 196.24 & Phenols \\
\hline 12. & 20.08 & 9.92 & Neophytadiene & $\mathrm{C}_{20} \mathrm{H}_{38}$ & 278.51 & Alkenes \\
\hline 13. & 20.94 & 2.92 & $\begin{array}{l}3,7,11,15-\text { Tetramethyl-2- } \\
\text { hexadecen-1-ol }\end{array}$ & $\mathrm{C}_{20} \mathrm{H}_{40} \mathrm{O}$ & 296.53 & Fatty acids \\
\hline 14. & 22.45 & 3.36 & Eicosanoic acid & $\mathrm{C}_{20} \mathrm{H}_{40} \mathrm{O}$ & 312.53 & Fatty acids \\
\hline 15. & 25.02 & 0.48 & Linoleic acid ethyl ester & $\mathrm{C}_{20} \mathrm{H}_{34} \mathrm{O}_{2}$ & 308.49 & Esters \\
\hline 16. & 25.30 & 4.75 & Phytol & $\mathrm{C}_{20} \mathrm{H}_{40} \mathrm{O}$ & 128.17 & Alcohol \\
\hline 17. & 26.37 & 1.00 & $\begin{array}{l}9,12,15-O c t a d e c a t r i e n o i c ~ a c i d, \\
\text { ethyl ester, }(Z, Z, Z)-\end{array}$ & $\mathrm{C}_{20} \mathrm{H}_{34} \mathrm{O}_{2}$ & 306.48 & Steroid \\
\hline 18. & 28.68 & 1.96 & Prostaglandin A2 & $\mathrm{C}_{20} \mathrm{H}_{30} \mathrm{O}_{4}$ & 334.41 & Lipids \\
\hline 19. & 29.44 & 1.32 & Lupulon & $\mathrm{C}_{26} \mathrm{H}_{38} \mathrm{O}_{4}$ & 414.60 & Fatty acid \\
\hline 20. & 29.82 & 0.48 & Docosanoic acid, butyl ester & $\mathrm{C}_{23} \mathrm{H}_{46} \mathrm{O}_{2}$ & 354.61 & Esters \\
\hline
\end{tabular}


Table 2. Chemical structure and its biological properties of the identified bioactive compounds

\section{S.No. Name of the compound \\ Biological activity \\ Chemical Structure}

Anti-inflammatory,

Hexadecanoic acid, 3hydroxy-, methyl ester

2. Tiglic acid

Antimicrobial

3. Hydroxylamine, O-decyl-

4. Tetradecane

5. Germacrene D

6. 2,4-Di-tert-butylphenol

7. á-copaene

7.epi-trans-sesquisabinene hydrate

9. Aromandendrene

10. Cubenol

6-Hydroxy-4,4,7a-trimethyl-

11. $5,6,7,7 a-$

tetrahydrobenzofuran-2(4H)one

Antimicrobial

Antimicrobial

Antimicrobial, antiinflammatory, and antioxidant

Antimicrobial

Antimicrobial

Antimicrobial

Flavoring agent antioxidant

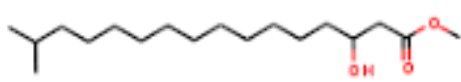<smiles>CC=C(C)C(=O)O</smiles><smiles>CCCCCCCCCCON</smiles><smiles>CCCCCCCCCCCCCC</smiles><smiles>C=C1C=CC(C(C)C)CCC(C)=CCC1</smiles><smiles>CC(C)(C)c1ccc(O)c(C(C)(C)C)c1</smiles><smiles>CC1=CCC2[C@@H](C(C)C)CC[C@]2(C)[C@H]1C</smiles>
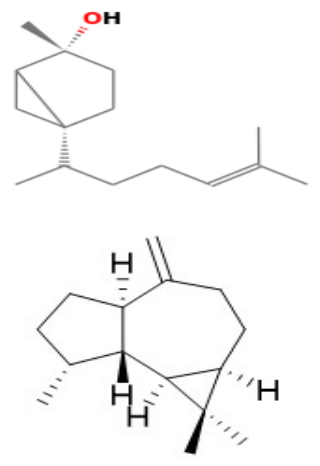

Membrane stabilizer,<smiles>CC1=CC2C(C(C)C)CCC(C)C2(O)CC1</smiles>

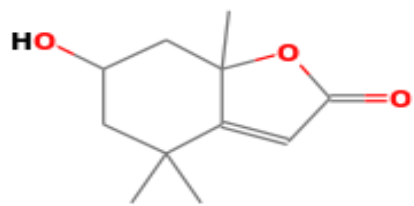


Table 2. Contd

12. Neophytadiene

13.

$3,7,11,15-$ Tetramethyl-2hexadecen-1-ol

14. Eicosanoic acid

15. Linoleic acid ethyl ester

16. Phytol

17. 9,12,15-Octadecatrienoic acid, ethyl ester, (Z,Z,Z)-

18. Prostaglandin A2

19. Lupulon

Antibiotic oxidant
Analgesic, antipyretic, anti-inflammatory, antimicrobial, and anti-

No activity reported<smiles>CC(=CCO)CCCC(C)CCCC(C)CCCC(C)C</smiles>

Anti-inflammatory

Anti-inflammatory

Antioxidant<smiles>C/C(=C\CO)CCC[C@H](C)CCC[C@H](C)CCCC(C)C</smiles>

Antiarthritic, Anticancer, Hepatoprotective, Antimicrobial, Antiasthma

Carbon metabolism
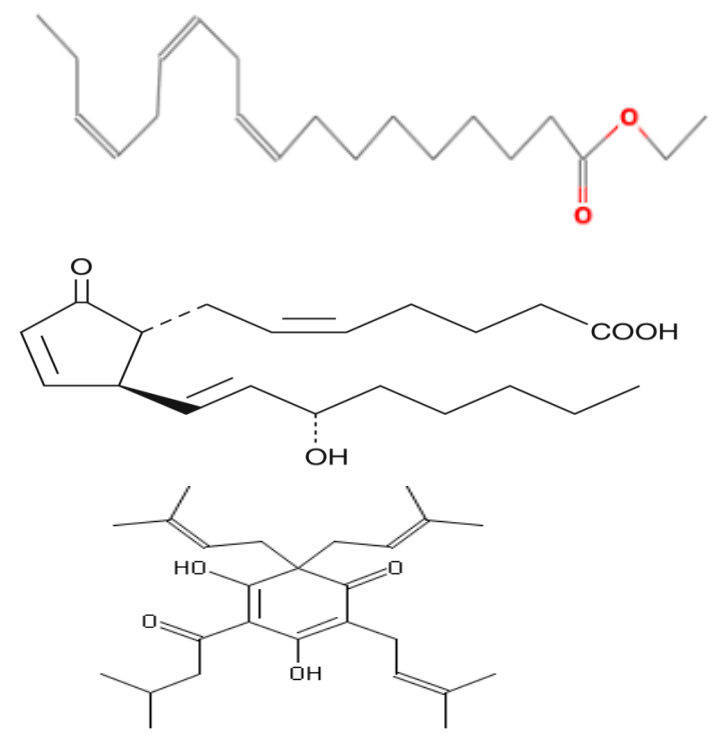

20. Docosanoic acid, butyl ester

Antimicrobial

Activity source: Dr. Duke's phytochemical and ethnobotanical databases (1992-2016)

\section{Chemical structure and its biological properties} As reported in Dr. Duke's Phytochemical and Ethnobotanical Databases (1992-2016), twenty identified compounds from the extract of P.corylifolia leaves have different chemical structures and various biological properties; and are presented in Table 2. This, the activities of the compounds screened during GC-MS analysis justify the traditional medicinal uses. Accordingly, various biological activities of identified bioactive com- pounds areantimicrobial, antioxidant, anti-inflammatory, anticancer activities, membrane stabilizer, flavouring agent, analgesic, antipyretic, hepatoprotective, antiasthmatic, and carbon metabolism. According to Rukshana et al. (2017), the identified compounds as Hexadecanoic acid, methyl ester, Pentadecanoic acid, 14-methyl-methyl ester, Ethyl 9,12,15octadecatrienoate and 4-(4-Chlorobenzoyl)-1cyclohexyl-5-tosylamino-1 $\mathrm{H}$-1,2,3-triazole are present 
in the leaf sample of Pergularia daemia, which were found to be an antiasthmatic and antimicrobial compounds. Apart form the pharmaceutical uses, $P$. corylifolia leaves are also used to control bacterial diseases of silkworm, Bomyx mori. Manimegalai et al. (2010) have revealed that $800 \mathrm{ppm}$ hexane leaf extracts of $P$. corylifolia, P. Amboinicus, and the gold standard, gentamycin (50 ppm) were effective against BmNPV infecting three different silkworm breeds, namely cross breed, PM X CSR 2 which showed the antimicrobial activity of $P$. corylifolia.

In the present study, GC analysis revealed all of the compounds in the leaf extract through specific qualitative and quantitative patterns. $P$. corylifolia has a wide range of biological qualities that can be utilized to cure a variety of ailments (Table 2). Among the identified compounds, phytol has been discovered to have antibacterial activity against Staphylococcus aureus by generating cell membrane disruption. The compound $9,12,15$ - Octadecatrienoic acid, ethyl ester $(Z, Z, Z)$ is a polyenoic fatty acid molecule has been reported to be anti-inflammatory, hypocholesterolemic, cancer preventative, hepatoprotective, nematicides, insectifuge, antihistaminic, anti-acne, 5-alpha reductase inhibitor, and anti-androgenic properties (Vohra and Kaur, 2011). The ethyl ester of linoleic acid is an unsaturated fatty acid with anti-inflammatory and cancer-preventive properties (Tulika and Mala, 2017).

\section{Conclusion}

As a result, this form of GCMS analysis is the first step toward understanding the nature of active ingredients in medicinal plants, and it will be useful for subsequent research. In the current study, the presence of valuable bioactive components such as phytol, Hexadecanoic acid- 3- hydroxy methyl ester, Neophytadiene, and Cubenolas revealed by GCMS analysis in the chloroform extract of $P$. corylifolia leaves have various biological activities. For further research,isolating particular phytochemical constituents and exposing them to biological action, on the other hand, it will almost certainly yield positive outcomes. Hence, it was concluded that the biological values of $P$. corylifolia leaves contain pharmacologically active substances that could improve their usage as a conventional drug.

\section{Conflict of interest}

The authors declare that they have no conflict of interest.

\section{REFERENCES}

1. Dr. Duke's Phytochemical and Ethnobotanical Databases (1992- 2016). U. S. Department of Agriculture, Agricultural Research Service. Retrieved from: http://phytoche m.nal.usda.gov.

2. International Union for Conservation of Nature and Natural Resources (2013). Guidelines on the conservation of medicinal plants. International Union for Conservation of $\mathrm{Na}$ ture and Natural Resources (IUCN), Gland Switzerland:

3. Kumar, S.M. \& Manimegalai, S. (2008). Evaluation of larvicidal effect of Lantana camara $L$. against mosquito species Aedes aegypti and Culex quinquefasciatus. Adv. Biol. Res.,2, 39-43.

4. Manimegalai, S., Rajeswari, T., Shanmugam, R. \& Rajalakshmi, G. (2010). Botanicals against Nuclear Polyhedrosis Virus infecting three breeds of mulberry silkworm, Bombyx mori L. Journal of Biopesticides, 3(1), $242-245$.

5. Rastogi R.P.\& Mehrotra, B.N.(1979). Compendium of Indian medicinal plants. (Vol 2), New Delhi, India: Central Drug Research, Lucknow and NISCAIR, 1979, 521.

6. Rukshana, M.S., Doss, A. \& Kumari PusphaRani,T.P. (2017). Phytochemical screening and GC-MS analysis of leaf extract ofPergulariadaemia (Forssk) Chiov. Asian Journal of Plant Science and Research, 7(1), 9-15.

7. Sathish, S.S., Janakiraman, N. \& Johnson, M. (2012). Phytochemical analysis of Vitex altissima L. Using UV-Vis, FTIR and GC-MS. Inter J of Pharma Sci and Drug Res. 4 (1), 56-62.

8. Siva, G., Sivakumar, S., Kumar, G.P., Vigneswaran, M., Vinoth, S., Selavan, A.M. \& Jayabalan, N. (2015). Optimization of elicitation with Jasmonic acid, characterization and antimicrobial activity of Psoralen from direct regenerated plants of Psoralea corylifolia L. Biocatalysis and Agricultural Biotechnology, 4(4), 624-631.

9. Sofowora, A., Ogunbodede, E. \& Onayade, A. (2013). The role and place of medicinal plants in the strategies for disease prevention. African Journal of Traditional, Complementary and Alternative Medicines, 10(5), 210-229.

10. Sridharan, S., Meena, V., Kavitha, V. \& Nayagam, A.A.J. (2011). GC-MS study and phytochemical profiling of Mimosa pudica L. J. Pharm. Res., 4, 741-742.

11. Tulika Tyagi \& Mala Agarwal. (2017). GC-MS analysis of invasive aquatic weed, Pistia stratiotes L. and Eichhornia crassipes (mart.) solms. Int. J. Curr. Pharm. Res., 9(3), 111-117. DOI: https://doi.org/10.22159/ijcpr.2017.v9i 3.19 970

12. Vohra, A. \& Kaur, H. (2011). Chemical investigation of medicinal plant Ajuga bracteosa. J. Nat. Prod. Plant Resour., 1(1), 37-45.

13. Zhang, X., Zhao, W., Wang, Y., Lu, j. \& Chen, X. (2016). The chemical constituents and bioactivities of Psoralea corylifolia Linn. : A review. The American Journal of Chinese Medicine, 44(01), 35-60. 